\title{
Application of optimized artificial intelligence algorithm to evaluate the heating energy demand of non-residential buildings at European level
}

\author{
G. Ciulla ${ }^{\text {a, }}$, A. D'Amico ${ }^{\text {a }}$, V. Lo Brano ${ }^{\text {a }}$, M. Traverso ${ }^{\text {b }}$ \\ ${ }^{a}$ University of Palermo, Department of Engineering (DI), Italy \\ ${ }^{\mathrm{b}}$ Institute of Sustainability in Civil Engineering, RWTH Aachen University, Germany
}

\section{A R T I C L E I N F O}

\section{Article history:}

Received 24 December 2018

Received in revised form

3 March 2019

Accepted 28 March 2019

Available online 6 April 2019

\section{Keywords:}

Building simulation

Thermal balance

High energy performance

Artificial neural network

Learning algorithm

Decision support tool

\begin{abstract}
A B S T R A C T
A reliable preliminary forecast of heating energy demand of a building by using a detailed dynamic simulation software typically requires an in-depth knowledge of the thermal balance, several input data and a very skilled user. The authors will describe how to use Artificial Neural Networks to predict the demand for thermal energy linked to the winter climatization of non-residential buildings. To train the neural network it was necessary to develop an accurate energy database that represents the basis of the training of a specific Artificial Neural Networks. Data came from detailed dynamic simulations performed in the TRNSYS environment. The models were built according to the standards and laws of building energy requirements in seven different European countries, for 3 cities in each country and with 13 different shape factors, obtaining 2184 detailed dynamic simulations of non-residential buildings designed with high energy performances. The authors identified the best ANN topology developing a tool for determining, both quickly and simply, the heating energy demand of a non-residential building, knowing only 12 well-known thermo-physical parameters and without any computational cost or knowledge of the thermal balance. The reliability of this approach is demonstrated by the low standard deviation less than $5 \mathrm{kWh} /\left(\mathrm{m}^{2} \cdot\right.$ year $)$.
\end{abstract}

(c) 2019 Elsevier Ltd. All rights reserved.

\section{Introduction}

Improvements in energy saving and energy efficiency are needed for the reduction of atmospheric emissions which contribute to the greenhouse effect. One of the main areas, where a considerable energy saving can be achieved, is the building sector, by attaining acceptable conditions of indoor thermal comfort [1]. The issue of limiting energy consumption pertaining to the building stock within the European Union has become the main objective of various legislative measures at international, national and local levels [2-4]. Indeed, about $40 \%$ of the European energy consumption is related to the building sector and most is linked to satisfying the heating energy demand. In order to achieve significant primary energy savings, many steps can be implemented by acting on the

\footnotetext{
* Corresponding author.

E-mail addresses: giuseppina.ciulla@unipa.it (G. Ciulla), antonio.damico@deim. unipa.it (A. D'Amico), lobrano@dream.unipa.it (V. Lo Brano), marzia.traverso@
} inab.rwth-aachen.de (M. Traverso). thermo-physical characteristics of the building envelope, on the geometry, and on the operational strategy of plants management as written in Ref. [5].

In order to mitigate this significant commitment to energy resources, the European Union has promulgated the "Energy Performance of Buildings Directive" (EPBD) [6]; it aims to impose the achievement of certain energy performances in the building heritage of new and old constructions. In order to maximize the energy performance of buildings, architects, designers and engineers have to optimize all those thermo-physical and plant parameters (thermal transmittance, shadowing, thermal plant components, plant regulation, etc.), while at the same time making indoor spaces comfortable [7-9]. The energy efficiency in buildings is related to the concept of a reduction in the energy demand needed to achieve desirable environmental conditions [10], and careful heating and cooling design is one of the best methods for reducing such energy costs [11]. To achieve this goal, all parameters that influence the thermal balance of the building must be carefully evaluated [12]. A building is a thermodynamic system that continuously carries out energy exchanges with the surrounding environment through the 


\begin{tabular}{|c|c|c|c|}
\hline \multicolumn{2}{|c|}{ Nomenclature } & $V$ & heated volume $\left[\mathrm{m}^{3}\right]$ \\
\hline & & \multicolumn{2}{|c|}{ ANN parameters } \\
\hline \multicolumn{2}{|c|}{ Model Parameters } & $A_{i}$ & activation potential \\
\hline & cooling energy demand $\left[\mathrm{kWh} /\left(\mathrm{m}^{2} \cdot\right.\right.$ year $\left.)\right]$ & $E_{w}$ & error function \\
\hline & total thermal capacity $\left[\mathrm{kWh} /\left(\mathrm{m}^{3} \cdot \mathrm{K}\right)\right]$ & $h$ & hidden layers \\
\hline$C D D$ & cooling Degree Days [K day] & $k$ & scale parameter \\
\hline$H_{d}$ & heating energy demand $\left[\mathrm{kWh} /\left(\mathrm{m}^{2} \cdot\right.\right.$ year $\left.)\right]$ & $K$ & tanh-sigmoid function shape \\
\hline$H D D$ & heating Degree Days [K day] & $T$ & number of iteration \\
\hline$Q_{G}$ & internal gains [ $\mathrm{kWh} /$ year] & $t_{i}$ & output pattern \\
\hline$Q_{S}$ & solar gains [kWh/year] & $v_{j k}$ & interconnection synaptic weights between $j$-th and $k$ - \\
\hline$Q_{T}$ & heat transmission losses [kWh/year] & & th layers \\
\hline$Q_{V}$ & ventilation losses [kWh/year] & $w_{i j}$ & interconnection synaptic weights between $i$-th and $j$ - \\
\hline$S$ & losses surface $\left[\mathrm{m}^{2}\right]$ & & th layers \\
\hline & opaque losses surface $\left[\mathrm{m}^{2}\right]$ & $\Delta w_{i j}$ & variation of the interconnection synaptic weights \\
\hline$S_{w}$ & window losses surface $\left[\mathrm{m}^{2}\right]$ & $x_{i}$ & input data \\
\hline$S / V$ & shape factor $\left[\mathrm{m}^{-1}\right]$ & $y_{i}$ & output data \\
\hline$U$ & thermal transmittance $\left.\left[\mathrm{W} /\left(\mathrm{m}^{2} \cdot \mathrm{K}\right)\right]\right)$ & $\alpha$ & momentum \\
\hline$U_{0}$ & overall U-value $\left[\mathrm{W} /\left(\mathrm{m}^{2} \cdot \mathrm{K}\right)\right]$ & $\eta$ & learning rate \\
\hline$U_{w}$ & window thermal transmittance $\left[\mathrm{W} /\left(\mathrm{m}^{2} \cdot \mathrm{K}\right)\right]$ & $\mu$ & specific input pattern \\
\hline$U_{o p}$ & overall opaque thermal transmittance $\left[\mathrm{W} /\left(\mathrm{m}^{2} \cdot \mathrm{K}\right)\right]$ & $\theta_{i}$ & neuron activation threshold \\
\hline
\end{tabular}

envelope [13]. Thus, the thermal-physical properties of the building envelope, the climate of the considered location, and the heating system have a direct impact on the building energy balance and, therefore, determine the intensity of energy demand. For this reason, changing and increasing the energy performance of a building requires the accurate knowledge of a great deal of data relating to the aforementioned quantities.

Many other authors have focused their studies on the evaluation of energy consumption of buildings, developing alternative models, as described and compared in Ref. [14]. For example, a numerical method to evaluate the non-linearity of the systems and its temporal response has been proposed [15] while in Ref. [16] the authors have described a new hybrid dynamic approach that links genetic programming with a grey model to forecast energy consumption.

In Ref. [17] the authors have proposed the adoption of a datadriven, feedforward decision framework for building cluster operation, employing noise-tolerant data fusion techniques, while in Ref. [18] a method for deploying models is described for the energy assessment of a building, this is useful for the control of the building at runtime using a system identification approach.

Recently, some works have appeared which modularly build a model of a building, which can be eventually used for predicting heating demand. Such methods use first-principle models or greybox model which can be eventually identified via neural networks or parameters estimation technique $[19,20]$.

A careful analysis of heating energy demand in the preliminary design stage and/or renovation stage allows the technician to identify the criticalities of the building-plant system and to select the most appropriate design choices; it strongly affects the consumption of energy and can improve the energy performance of the building. To simplify the calculation procedures, several simulation tools [21] have been developed and tested [22]. All these methods and tools, briefly summarized above, allow a very precise evaluation of the energy performance but need a huge amount of technical information and many parameters, which are not always easy to find. Furthermore, a detailed and in-depth knowledge of relevant software and great skill in understanding the underlying physical phenomena are required. To accelerate the phase of preliminary assessment, it might be easier to use a simplified model which allows the evaluation of the energy demand with a good level of accuracy and without excessive computational cost or user experience.

An alternative approach to the traditional methods for the definition of the building energy balance (e.g. those characterized by a steady state approach $[23,24]$ or those characterized by a dynamic approach of the problem [21]) is presented through the use of evolutionary algorithms that are based on the operating logic of AI [25]. Although the evolutionary algorithms do not know in detail the mathematical equations that analytically describe the dynamic behaviour of the systems, they exploit the correlations existing between large amounts of data in order to identify functional connections between input and output. Indeed, one of the most representative strengths of the systems based on this type of model lies in their inherent ability to build a strong relationship between input and output, when in another way this would be difficult, or even impossible. These kinds of models are very useful whenever the phenomenon to be studied is characterized by considerable complexity and interdependence of many factors for which the identification, and in particular calibration, of an analytical deterministic and/or statistical (or otherwise) model is rather complicated; furthermore, often these tools are not validated and their reliability is not very high.

In this contribution, the authors will show how it is possible to use Artificial Neural Networks (ANNs) to predict the demand for thermal energy connected to the winter climatization of nonresidential buildings [26].

\section{Materials and method}

In order to determine the heating energy demand, it was necessary to study the influence of various parameters that come into play in the overall energy balance of the building.

The database used by the ANNs was built using results that emerged from over 2184 detailed dynamic simulations performed in the TRNSYS environment [27]. After the implementation of an "ideal building" model built according to the highest standards and laws of energy requirements in different European countries, these models were calibrated with empirical data reported in the scientific literature. Taking into consideration the differences that exist in the regulations and technical standards about the building 
energy performance of various European countries, the authors developed several detailed dynamic simulation models that refer to seven countries: Germany, Spain, the United Kingdom, Belgium, Italy, France, and Sweden. Moreover, to take into account the different climatic characteristics of each nation, three locations were evaluated for each country which represent the hottest, the coolest and the mildest climate. The shape factors of buildings, which represent the ratio between the total of the loss surfaces to the gross heated volume of a building, were varied from 0.24 to 0.90 obtaining 273 models. Each model is characterized by 13 main parameters which directly influence the energy performance of the building system. Finally, to take into account the effects of solar radiation, each building model was considered in eight different positions with respect to cardinal south, with a step of $45^{\circ}$ [28].

These data represent the database used to train different ANN architectures. In this paper, only the best-obtained results from optimal ANN are reported; the validation of the ANNs was carried out by using a set of data corresponding to $15 \%$ of the initial set which were not used to train the ANNs. The obtained good results (determination coefficient values $\left(\mathrm{R}^{2}\right)$ higher than 0.95 and Mean Absolute Percentage Error (MAPE) lower than 9\%) show the suitability of the calculation method based on the use of adaptive systems for the evaluation of energy performance of buildings. The developed tool provides a practical, efficient and fast methodology for forecasting energy consumption for winter air-conditioning of non-residential buildings in the European Union, taking into account different requirements in different locations. This tool could help in energy planning, in accelerating the design process and in supporting public administration in the evaluation of the energy demand of a large set of building clusters.

\subsection{Artificial neural network}

AI techniques are implemented in several applications due to their strong reasoning, fault tolerance, flexibility and generalization capabilities. As one of the most popular AIs, the ANN, which is a mathematical paradigm imitating the behaviour of biological neural networks, has been implemented to solve many practical problems in different fields. The attempt to simulate the behaviour of the biological neural system conduct to the implementation of the ANNs. ANN is a collection of individually interconnected processing units acting as parallel-distributed computing networks. Unlike conventional computers which are programmed to carry out specific functions, ANNs, working as human brain-like mathematical models, can learn from examples and remove the need to use complex mathematical formulas or expensive physical models. ANNs are fault tolerant and can work with noisy data, providing high-speed generalization capabilities for unseen input [29]. Furthermore, ANNs have particular adaptation characteristics that also allow the resolution of highly non-linear problems where it is particularly difficult to find analytical formulations that link the input data to the output data [30]. Different to other statistical or parametric methods, ANNs are able to derive non-explicit relationships from a large mass of correlated data by exploiting the high computing capabilities of current computers; in this way, ANNs have become a particularly successful approach to solving different problems in fields that are very different from each other [31]. Application of neuro-computing does not require the provision of particular hypotheses on the investigated physical phenomenon, they can simply be linked to a black box whose internal functioning is not known [32]. In order to better understand these systems, a basic understanding of the biological neuron is required. A biological neuron can be seen as a cell (cell body) that has many inputs (dendrites) and one output (axon). A biological neural network is composed of many neurons whose axons are linked to the dendrites of other neurons through links which are called synapses (Fig. 1).

ANNs have surprisingly similar characteristics to those of the human brain; an empirical ability to learn, limited precision associated with high elasticity of input interpretation, and extrapolation and generalization capabilities. ANNs have a distributed memory structure, are adaptive, able to modify themselves independently in response to the stimuli received during training, and their learning does not suffer from the existence of possible non-linear links between the input/output pairs used for training.

Artificial neurons are arranged in layers; each neuron is connected and exchanges information with other neurons and/or with itself, and the interconnectivity defines the topology of the ANN. Neurons sum up the weighted contributions that reach them through synaptic connections, filter them through a function, and produce an output. In general, the effect of an input signal $x_{j}$ on the $i$-th postsynaptic neuron is simply equal to the product $w_{i j} \times x_{j}$ where $w_{i j}$ is the weight of the corresponding connection. The net input of this neuron, defined as activation potential $A_{i}$, is equal to:

$$
A_{i}=\sum_{j} w_{i j} x_{j}-\vartheta_{i}
$$

where $\vartheta_{i}$ is the threshold activation value of the neuron. An output is obtained only if the signal is propagated through a particular activation function:

$y_{i}=\Phi\left(A_{i}\right)=\Phi\left(\sum_{j} w_{i j} x_{j}-\vartheta_{i}\right)$

The activation function can also limit the range of values that the signal can take. In fact, the values of input and output variables are often normalized to reduce certain numerical instabilities and to improve ANN performance. Typically, the same activation function is used for all neurons in the network, even if it is not necessary [34]. Among the most common mathematical functions which can be used for activation threshold in ANNs, there are linear, step, sigmoid, and hyperbolic tangents.

As already mentioned, the ANN is made up of blocks of neurons connected to each other so as to discover the relationships between correlated data [35-38]. Through the training process, the neural network determines the functions that describe the separation lines between the various categories (decision boundaries). The characteristics of the separation functions are linked to the network weights. At each training step, the weights are updated directly according to the characteristics of the data presented to the network, regardless of any hypothesis about the statistical distribution of the data or knowledge of the physical laws governing the phenomenon.

\section{i-thneuron layers}

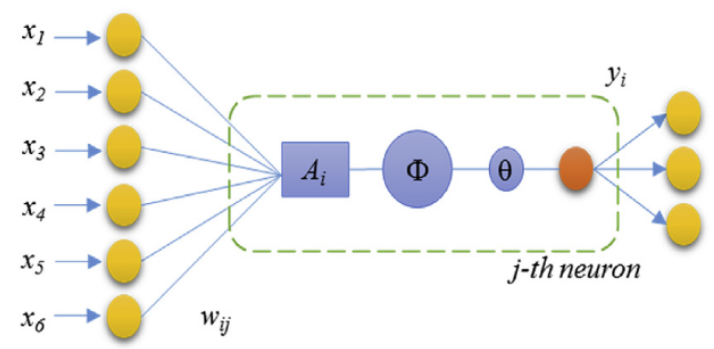

Fig. 1. [33] Artificial neuron schema. 
Schematically, three different blocks of neurons can be recognized in a simple feed forward neural network: input, hidden, and output neurons (Fig. 2); the first collects the inputs $x_{i}$; the last issues the outputs $y_{i}$ and the hidden layer $h_{i}$ connects inputs to outputs.

The architecture of a simple neural network of this type provides the flow of information in a single direction, from the input layer to the output layer, without forming any type of cycle or loop. Except for the input nodes, each node is a neuron or processing element (PE) with an activation function [39]. As you can see, this structure is aimed at constructing an approximate function describing the behaviour of very complicated systems by ensembles of simpler functions [40].

\subsection{Building energy balance}

In the field of building energy planning, often a first summary evaluation of the indoor heating/cooling load is necessary. Nevertheless, this evaluation is often very complex: the thermal balance of the buildings depends on several mutually linked factors. Generally, the standard conditions to be maintained in indoor environments are represented by two ranges of temperature: $18-20^{\circ} \mathrm{C}$ in winter and $24-26^{\circ} \mathrm{C}$ in summer [41]. As depicted in Fig. 3, the energy balance of a building is characterized by energy losses and gains; furthermore, the climate context, as well as the building construction type and its use are key parameters.

By solving the system of equations describing the building thermal balance, it is possible to assess the Heating $\left(H_{d}\right)$ and Cooling $\left(C_{d}\right)$ demands that represent the necessary amount of energy to maintain the desired ambient temperature in winter or summer [42].

For example, according to the approach described in Ref. [43], the heating energy demand in kilowatt-hours can be estimated by:

$E_{d}=\frac{86400}{3.6 \times 10^{6}} \cdot D D \cdot\left(Q_{V}+\sum A \cdot U\right)=0.024 \cdot D D \cdot U^{\prime}$

where.

- $Q_{V}$ is the ventilation loss term $[\mathrm{W} / \mathrm{K}]$;

- $A$ is the surface area $\left[\mathrm{m}^{2}\right]$;

- $U$ is the thermal transmittance $\left[\mathrm{W} / \mathrm{m}^{2} \mathrm{~K}\right]$;

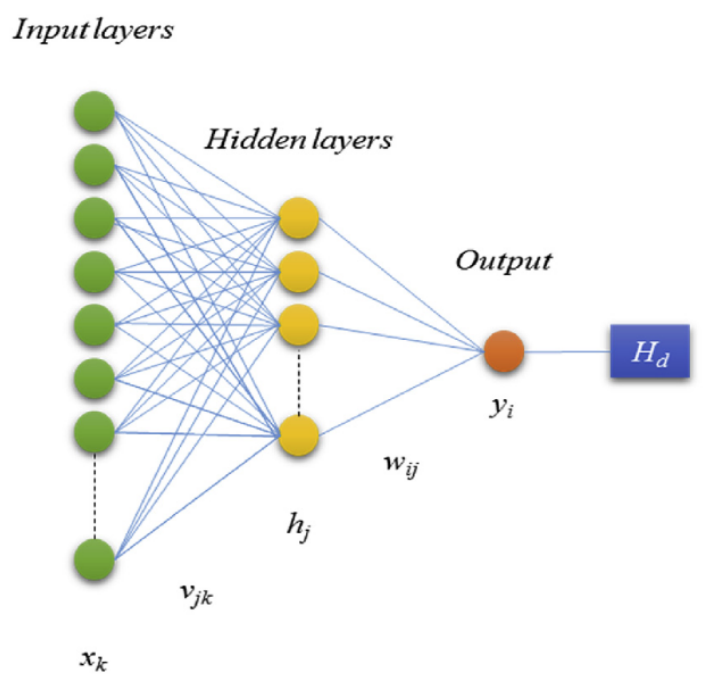

Fig. 2. An ANN schema.

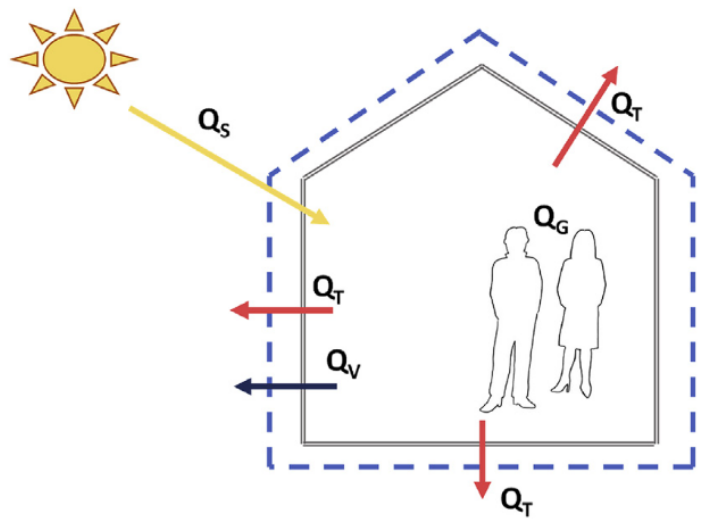

Fig. 3. Building energy balance.

- $D D$ are the Degree Days [K day].

Generally, it is possible to state that $H_{d}$ or $C_{d}$ are functions of:

$$
\begin{aligned}
H_{d} & =f\left(H D D, Q_{T}, Q_{V}, Q_{S} Q_{G}\right) \quad \text { and } \quad C_{d} \\
& =f^{\prime}\left(C D D, Q_{T}, Q_{V}, Q_{S} Q_{G}\right)
\end{aligned}
$$

where.

- $H D D$ is the Heating Degree Days [K day];

- $C D D$ is the Cooling Degree Days [K day];

- $Q_{T}$ is the transmittance losses and are dependent on the construction type of the building and also on the thermal transmittance of all the enclosure surfaces [kWh/year];

- $Q_{V}$ is the ventilation loss term reported in the actual standards and laws [23] [kWh/year];

- $Q_{G}$ are the internal gains reported in the actual standards and laws [23] and are dependent on the intended use [kWh/year];

- $Q_{S}$ are the solar gains that depend on the relationship between the glass surface and the opaque surface and on the exposure [kWh/year].

Eqs. (3) and (4) show that the energy demand is strongly correlated to the climate context (DD and $Q s)$, the intended use $(Q v)$ and the thermo-physical parameter $\left(U^{\prime}\right)$. This last parameter represents the mean quality of the building envelope, but does not take into account the geometry or orientation of the building, thus neglecting important parameters which could influence the energy balance (e.g. it does not evaluate the area of loss surface to heated/ cooled volume, $S / V)$ [28].

This simplified and steady state method was indicated to identify, in a fast way, those variables that describe the physical phenomenon and are fundamental in the building thermal balance. The identification of the main parameters was necessary to select the essential input data that constitutes the base to create and store numerical data used to train an ANN.

\subsubsection{European climate}

Europe is a region that includes a continental portion and peninsulas, interrupted by the Black Sea and the Baltic Sea. It is one of the smallest continents in the world, but it is the third most populous continent. The natural border of Europe is largely made up of its seas: on the north, it is bounded by the Arctic Ocean, and to the west and south by the Atlantic Ocean, the Mediterranean and the Black Sea. The western part of the European continent is characterized by a climate called Temperate Oceanic climate, strongly influenced by the Gulf Stream. This marine current coming 
from central American regions carries a great quantity of heat, keeping a moderate air temperature (considering the latitude) over North-Western Europe during the winter. On the contrary, Eastern Europe is characterized by a drier, continental climate and Southern Europe enjoys a Mediterranean climate (with distinct wet and dry seasons) [44].

Our study attempts to collect at least one example of all possible climatic situations that can be observed in the European Union and for this reason three different locations for each of the aforementioned countries were chosen. As shown in Table 1, for each city the HDD values representing the maximum, minimum, and mean national values were evaluated.

\subsubsection{Database creation}

Generally, the implementation of an ANN to solve a problem requires the presence of a suitable database set in which the output data wanted by the network is strongly related to one or more data considered as input. In this case, the output data is represented by the heating energy demand, while the input data are all the data that describe the building balance, such as: the constructive typology, the intended use and the climate context.

To create a reliable database the authors have used the results obtained by dynamic models of an ideal office building, built in the TRNSYS environment [27], and designed with high energy performance (ideal building) according to the minimum standard requirements of each European country.

As indicated in Ref. [28] an "ideal building" model having high energy performance according to the minimum standard requirements was designed. In detail, the "ideal building" was created with thirteen different shape factors (from 0.24 to 0.9 ) and each model was simulated in seven European countries with different climates.

For each country, three cities were chosen by identifying three different HDDs. The geometric characteristics of the thirteen "ideal building" models are summarized in Ref. [28].

Each model was built with respect to the European standard on energy consumption of office buildings, EN ISO 13,790: 2008 [23], and by implementing detailed information, such as thermophysical characteristics of the building envelope, glazed-opaque surface ratio, employment rate, internal gains, heating period, and switching on/off of the heating system. For each model, the authors defined the stratigraphy of the walls, roofs, and floors by ensuring that U-values respect the standard national limits [13]. To evaluate the average energy performance of a building as a function of incident solar radiation, each model for each city was simulated eight times, varying the orientation of the building by $45^{\circ}$ and averaging the obtained results. By integrating and averaging the simulation results, annual heating energy demands were calculated.

In total 13 models, with different shape factors ranging from 0.24 to 0.9 , were simulated eight times in 7 different countries for 3 different cities obtaining 2184 different simulations connoted by hourly time-step that were stored in a MySQL database $[28,47,48]$. The collected data are related to the following parameters:

1. Heating Degree Days HDD [K];

2. Shape factor $S / V\left[\mathrm{~m}^{-1}\right]$;

3. Window surface $S_{w}\left[\mathrm{~m}^{2}\right]$;

4. Opaque Surface $S_{o p}\left[\mathrm{~m}^{2}\right]$;

5. Window thermal transmittance $U_{w}\left[\mathrm{~W} /\left(\mathrm{m}^{2} \cdot \mathrm{K}\right)\right]$ :

6. Overall opaque thermal transmittance $U_{o p}\left[\mathrm{~W} /\left(\mathrm{m}^{2} \cdot \mathrm{K}\right)\right]$;

7. Overall thermal transmittance $U_{0}\left[\mathrm{~W} /\left(\mathrm{m}^{2} \cdot \mathrm{K}\right)\right]$;

8. Solar gains $Q_{s}[\mathrm{kWh} /$ year];

9. Heating operating hours $h[\mathrm{~h}]$;

10. Total thermal capacity $C_{T}\left[\mathrm{kWh} /\left(\mathrm{m}^{3} \cdot \mathrm{K}\right)\right]$;

11. Internal gains $Q_{G}[\mathrm{kWh} /$ year];

12. Wind speed $v[\mathrm{~m} / \mathrm{s}]$;

13. Heating energy demand $H_{d}\left[\mathrm{kWh} /\left(\mathrm{m}^{2} \cdot\right.\right.$ year $\left.)\right]$.

Table 2 shows the results obtained for Italy:

\section{Design of the ANNs}

As previously explained, in an ANN, the link between input and output is not defined by explicit interdependence relationships but is obtained through an empirical training process based on declared corresponding inputs/outputs. The neural network learns and builds the function that binds output with the input through

Table 1

Climate parameters and heating period of examined European cities.

\begin{tabular}{|c|c|c|c|c|c|}
\hline European Country & City & $H D D$ [K/day $]$ & Wind speed [m/s] & Heating period & Operating hours [h] \\
\hline \multirow[t]{3}{*}{ Belgium } & Hubert & 3190.72 & 3.86 & $1^{5 \text { th }}$ September- 15 th May & 1512 \\
\hline & Bruxelles & 2239.30 & 3.51 & $15^{\text {th }}$ October- $30^{\text {th }}$ April & 1152 \\
\hline & Liège & 1975.16 & 3.88 & $1^{\text {st }}$ November- 15 th March & 824 \\
\hline \multirow[t]{3}{*}{ France } & Bordeaux & 1602.05 & 3.42 & $1^{\text {st }}$ November- 15 th March & 888 \\
\hline & Bourge & 2226.74 & 3.73 & $1^{\text {st }}$ November-31st March & 1064 \\
\hline & Nice & 1123.38 & 3.94 & $1^{\text {st }}$ November-31st March & 800 \\
\hline \multirow[t]{3}{*}{ Germany } & Fichtelberg & 4982.19 & 6.63 & $1^{\text {st }}$ September- 15 th June & 1696 \\
\hline & Frankfurt & 2829.51 & 2.34 & $15^{\text {th }}$ October- $30^{\text {th }}$ May & 1240 \\
\hline & Hof & 3425.53 & 2.65 & $15^{\text {th }}$ October- $30^{\text {th }}$ May & 1328 \\
\hline \multirow[t]{3}{*}{ Italy } & Palermo & 662.65 & 3.73 & $1^{\text {st }}$ December- 31st Mach & 712 \\
\hline & Venice & 2077.81 & 2.50 & $15^{\text {th }}$ October- $30^{\text {th }}$ April & 808 \\
\hline & Sestriere & 5265.20 & 5.83 & $15^{\text {th }}$ September- 15 th June & 1608 \\
\hline \multirow[t]{3}{*}{ Spain } & Seville & 702.80 & 4.05 & $15^{\text {th }}$ November- 15 th March & 488 \\
\hline & Madrid & 1615.32 & 4.10 & $1^{\text {st }}$ November-31st March & 888 \\
\hline & Salamanca & 2379.29 & 3.29 & $15^{\text {th }}$ October- 15 th May & 1240 \\
\hline \multirow[t]{3}{*}{ Sweden } & Lund & 3202.40 & 6.39 & $1^{\text {st }}$ September- $30^{\text {th }}$ June & 1240 \\
\hline & Umea & 5299.05 & 3.32 & $1^{\text {st }}$ September- $30^{\text {th }}$ June & 1696 \\
\hline & Kiruna & 6986.21 & 2.68 & $15^{\text {th }}$ October- 15 th May & 1784 \\
\hline \multirow[t]{3}{*}{ UK } & Camborne & 2026.30 & 5.38 & $1^{\text {st }}$ November- 15 th May & 1088 \\
\hline & Birmingham & 2773.73 & 4.32 & $1^{\text {st }}$ October- 15 th May & 1336 \\
\hline & Aviemore & 3483.33 & 3.55 & $1^{\text {st }}$ September-15th May & 1512 \\
\hline
\end{tabular}

Data provided by the Meteonorm software [45] have been used to characterize the climate of each location. The software allows the use of real data monitored by a network of weather stations in the period 2000-2009. Taking into account the activity periods of HVAC systems defined by the various national regulations, it was therefore possible to calculate the HDD indexes $[28,46]$. 
Table 2

Characteristics and features of the Italian models.

\begin{tabular}{|c|c|c|c|c|c|c|c|c|c|c|c|c|c|c|}
\hline Model & City & $H D D$ & $S / V$ & $S_{w}$ & $S_{o p}$ & $U_{w}$ & $U_{o p}$ & $U_{0}$ & $Q_{s}$ & $h$ & $v$ & $C_{T}$ & $Q_{G}$ & $H_{d}$ \\
\hline \multirow[t]{3}{*}{ A } & IT-Palermo & 662.65 & 0.24 & 860.68 & 4935.85 & 2.76 & 0.42 & 0.76 & $46,838.08$ & 712 & 3.73 & 0.0690 & $647,566.44$ & 1.33 \\
\hline & IT-Venezia & 2077.81 & 0.24 & 860.68 & 4935.85 & 2.76 & 0.42 & 0.76 & $50,605.89$ & 808 & 2.50 & 0.0690 & $647,566.44$ & 20.70 \\
\hline & IT-Sestriere & 5265.20 & 0.24 & 860.68 & 4935.85 & 2.76 & 0.42 & 0.76 & $173,001.52$ & 1608 & 5.83 & 0.0690 & $647,566.44$ & 49.34 \\
\hline \multirow[t]{3}{*}{ B } & IT-Palermo & 662.65 & 0.27 & 838.80 & 4015.15 & 2.76 & 0.42 & 0.82 & $45,567.40$ & 712 & 3.73 & 0.0656 & $483,948.36$ & 1.46 \\
\hline & IT-Venezia & 2077.81 & 0.27 & 838.80 & 4015.15 & 2.76 & 0.42 & 0.82 & $49,223.84$ & 808 & 2.50 & 0.0656 & $483,948.36$ & 21.91 \\
\hline & IT-Sestriere & 5265.20 & 0.27 & 838.80 & 4015.15 & 2.76 & 0.42 & 0.82 & $166,952.85$ & 1608 & 5.83 & 0.0656 & $483,948.36$ & 50.33 \\
\hline \multirow[t]{3}{*}{ C } & IT-Palermo & 662.65 & 0.32 & 545.60 & 4094.41 & 2.76 & 0.41 & 0.69 & $29,550.93$ & 712 & 3.73 & 0.0226 & $293,940.19$ & 5.23 \\
\hline & IT-Venezia & 2077.81 & 0.32 & 545.60 & 4094.41 & 2.76 & 0.41 & 0.69 & $31,929.21$ & 808 & 2.50 & 0.0226 & $293,940.19$ & 35.86 \\
\hline & IT-Sestriere & 5265.20 & 0.32 & 545.60 & 4094.41 & 2.76 & 0.41 & 0.69 & $109,292.63$ & 1608 & 5.83 & 0.0226 & $293,940.19$ & 78.19 \\
\hline \multirow[t]{3}{*}{ D } & IT-Palermo & 662.65 & 0.35 & 460.34 & 1654.66 & 2.76 & 0.43 & 0.93 & $24,271.69$ & 712 & 3.73 & 0.1841 & $483,948.36$ & 2.89 \\
\hline & IT-Venezia & 2077.81 & 0.35 & 460.34 & 1654.66 & 2.76 & 0.43 & 0.93 & $26,225.68$ & 808 & 2.50 & 0.1841 & $483,948.36$ & 31.02 \\
\hline & IT-Sestriere & 5265.20 & 0.35 & 460.34 & 1654.66 & 2.76 & 0.43 & 0.93 & $90,371.86$ & 1608 & 5.83 & 0.1841 & $483,948.36$ & 64.60 \\
\hline \multirow[t]{3}{*}{ E } & IT-Palermo & 662.65 & 0.40 & 318.26 & 1271.74 & 2.76 & 0.42 & 0.89 & $16,979.68$ & 712 & 3.73 & 0.0585 & $459,580.17$ & 3.91 \\
\hline & IT-Venezia & 2077.81 & 0.40 & 318.26 & 1271.74 & 2.76 & 0.42 & 0.89 & $18,342.81$ & 808 & 2.50 & 0.0585 & $459,580.17$ & 35.31 \\
\hline & IT-Sestriere & 5265.20 & 0.40 & 318.26 & 1271.74 & 2.76 & 0.42 & 0.89 & $62,475.56$ & 1608 & 5.83 & 0.0585 & $459,580.17$ & 72.16 \\
\hline \multirow[t]{3}{*}{$\mathrm{F}$} & IT-Palermo & 662.65 & 0.50 & 530.91 & $11,455.80$ & 2.76 & 0.41 & 0.51 & $29,213.65$ & 712 & 3.73 & 0.0824 & $293,940.19$ & 10.94 \\
\hline & IT-Venezia & 2077.81 & 0.50 & 530.91 & $11,455.80$ & 2.76 & 0.41 & 0.51 & $31,562.32$ & 808 & 2.50 & 0.0824 & $293,940.19$ & 42.65 \\
\hline & IT-Sestriere & 5265.20 & 0.50 & 530.91 & $11,455.80$ & 2.76 & 0.41 & 0.51 & $107,276.82$ & 1608 & 5.83 & 0.0824 & $293,940.19$ & 89.16 \\
\hline \multirow[t]{3}{*}{ G } & IT-Palermo & 662.65 & 0.56 & 454.66 & $10,745.34$ & 2.76 & 0.41 & 0.50 & $24,969.20$ & 712 & 3.73 & 0.1056 & $459,580.17$ & 9.28 \\
\hline & IT-Venezia & 2077.81 & 0.56 & 454.66 & $10,745.34$ & 2.76 & 0.41 & 0.50 & $26,976.68$ & 808 & 2.50 & 0.1056 & $459,580.17$ & 37.41 \\
\hline & IT-Sestriere & 5265.20 & 0.56 & 454.66 & $10,745.34$ & 2.76 & 0.41 & 0.50 & $91,735.03$ & 1608 & 5.83 & 0.1056 & $459,580.17$ & 78.31 \\
\hline \multirow[t]{3}{*}{$\mathrm{H}$} & IT-Palermo & 662.65 & 0.58 & 303.10 & 5496.89 & 2.76 & 0.41 & 0.53 & $16,450.43$ & 712 & 3.73 & 0.0902 & $836,139.47$ & 9.42 \\
\hline & IT-Venezia & 2077.81 & 0.58 & 303.10 & 5496.89 & 2.76 & 0.41 & 0.53 & $17,774.76$ & 808 & 2.50 & 0.0902 & $836,139.47$ & 39.63 \\
\hline & IT-Sestriere & 5265.20 & 0.58 & 303.10 & 5496.89 & 2.76 & 0.41 & 0.53 & $60,842.73$ & 1608 & 5.83 & 0.0902 & $836,139.47$ & 81.62 \\
\hline \multirow[t]{3}{*}{ I } & IT-Palermo & 662.65 & 0.62 & 153.29 & 1251.30 & 2.76 & 0.41 & 0.67 & 8210.59 & 712 & 3.73 & 0.0874 & $165,341.36$ & 11.30 \\
\hline & IT-Venezia & 2077.81 & 0.62 & 153.29 & 1251.30 & 2.76 & 0.41 & 0.67 & 8870.57 & 808 & 2.50 & 0.0874 & $165,341.36$ & 54.94 \\
\hline & IT-Sestriere & 5265.20 & 0.62 & 153.29 & 1251.30 & 2.76 & 0.41 & 0.67 & $30,297.10$ & 1608 & 5.83 & 0.0874 & $165,341.36$ & 107.36 \\
\hline \multirow[t]{3}{*}{ L } & IT-Palermo & 662.65 & 0.69 & 291.74 & 4078.26 & 2.76 & 0.41 & 0.56 & $16,037.81$ & 712 & 3.73 & 0.1052 & $165,468.547$ & 9.07 \\
\hline & IT-Venezia & 2077.81 & 0.69 & 291.74 & 4078.26 & 2.76 & 0.41 & 0.56 & $17,324.91$ & 808 & 2.50 & 0.1052 & $165,468.547$ & 41.13 \\
\hline & IT-Sestriere & 5265.20 & 0.69 & 291.74 & 4078.26 & 2.76 & 0.41 & 0.56 & $58,565.63$ & 1608 & 5.83 & 0.1052 & $165,468.547$ & 82.51 \\
\hline \multirow[t]{3}{*}{ M } & IT-Palermo & 662.65 & 0.70 & 254.60 & 5817.39 & 2.76 & 0.41 & 0.50 & $13,867.16$ & 712 & 3.73 & 0.1181 & $247,754.888$ & 9.29 \\
\hline & IT-Venezia & 2077.81 & 0.70 & 254.60 & 5817.39 & 2.76 & 0.41 & 0.50 & $14,984.87$ & 808 & 2.50 & 0.1181 & $247,754.888$ & 37.99 \\
\hline & IT-Sestriere & 5265.20 & 0.70 & 254.60 & 5817.39 & 2.76 & 0.41 & 0.50 & $51,438.65$ & 1608 & 5.83 & 0.1181 & $247,754.888$ & 77.61 \\
\hline \multirow[t]{3}{*}{$\mathrm{N}$} & IT-Palermo & 662.65 & 0.76 & 155.62 & 2255.12 & 2.76 & 0.41 & 0.56 & 8443.36 & 712 & 3.73 & 0.0400 & $103,338.35$ & 8.00 \\
\hline & IT-Venezia & 2077.81 & 0.76 & 155.62 & 2255.12 & 2.76 & 0.41 & 0.56 & 9122.14 & 808 & 2.50 & 0.0400 & $103,338.35$ & 37.38 \\
\hline & IT-Sestriere & 5265.20 & 0.76 & 155.62 & 2255.12 & 2.76 & 0.41 & 0.56 & $31,082.33$ & 1608 & 5.83 & 0.0400 & $103,338.35$ & 74.91 \\
\hline \multirow[t]{3}{*}{$\mathrm{O}$} & IT-Palermo & 662.65 & 0.90 & 300.45 & 2372.40 & 2.76 & 0.41 & 0.68 & $16,412.41$ & 712 & 3.73 & 0.1215 & $486,170.64$ & 9.66 \\
\hline & IT-Venezia & 2077.81 & 0.90 & 300.45 & 2372.40 & 2.76 & 0.41 & 0.68 & $17,726.97$ & 808 & 2.50 & 0.1215 & $486,170.64$ & 49.75 \\
\hline & IT-Sestriere & 5265.20 & 0.90 & 300.45 & 2372.40 & 2.76 & 0.41 & 0.68 & $59,652.30$ & 1608 & 5.83 & 0.1215 & $486,170.64$ & 94.63 \\
\hline
\end{tabular}

In Appendix A, all data for each model in each city are collected; this matrix represents the dataset used to train the ANN to determine the heating energy demand as a unique output.

the presentation of a large number of input/output examples correlated with each other. For each input example presented to the network during the learning process, a calculated output that differs by a certain amount from the exact output is provided. The training algorithm modifies some network parameters at each iteration to bring the output to the exact system response. These parameters are the numerical weights associated with the synaptic connections between the neurons of the network.

Based on this approach, the previous database was used to train an ANN to immediately identify the $H_{d}$ value without the solution of an energy balance. After the pre-processing phase, the authors explored different topologies of ANN and four ANNs were developed in this study for the evaluation of heating energy demand. The basic configuration of ANN was the Multi-Layer Perceptron (MLP) investigating two different topologies and for each of them two different configurations, varying the number of hidden layers and the number of neurons. For the modelling of physical systems and the resolution of regression problems, a feed-forward Back-Propagation MLP structure is commonly used. The main advantages of MLP structures are that, they are easy to use and they require relatively little memory and are generally fast; also, MLP structures have the ability to learn non-linear and complex relationships between input and output patterns, which would be difficult to model with conventional methods.

A topology: MLP with one hidden layer (Fig. 4):
- A1: hidden layer with 8 neurons;

- A2: hidden layer with 30 neurons.

B topology: MLP with two hidden layers (Fig. 5):

- B1: first hidden layer with 400 neurons and second hidden layer with 120 neurons;

- B2: first hidden layer with 500 neurons and second hidden layer with 250 neurons.

Figs. 4 and 5 represent the schemas of A1 and B1 topologies respectively, and in these configurations, it is possible to identify different activation functions. An activation function determines the response that a neuron is capable of delivering. In this paper, the authors used two continuous activation functions: linear and hyperbolic tangent functions (tanh-sigmoid) [49].

In a linear function, a number of such linear neurons perform a linear transformation of the input vector:

$y_{i}=\Phi\left(A_{i}\right)=k A_{i}$

in which $k$ is a scale parameter.

A tanh-sigmoid function instead produces an output value between -1 and 1 ; furthermore, the tanh-sigmoid function is continuous and differentiable. Generally, the tanh-sigmoid function 


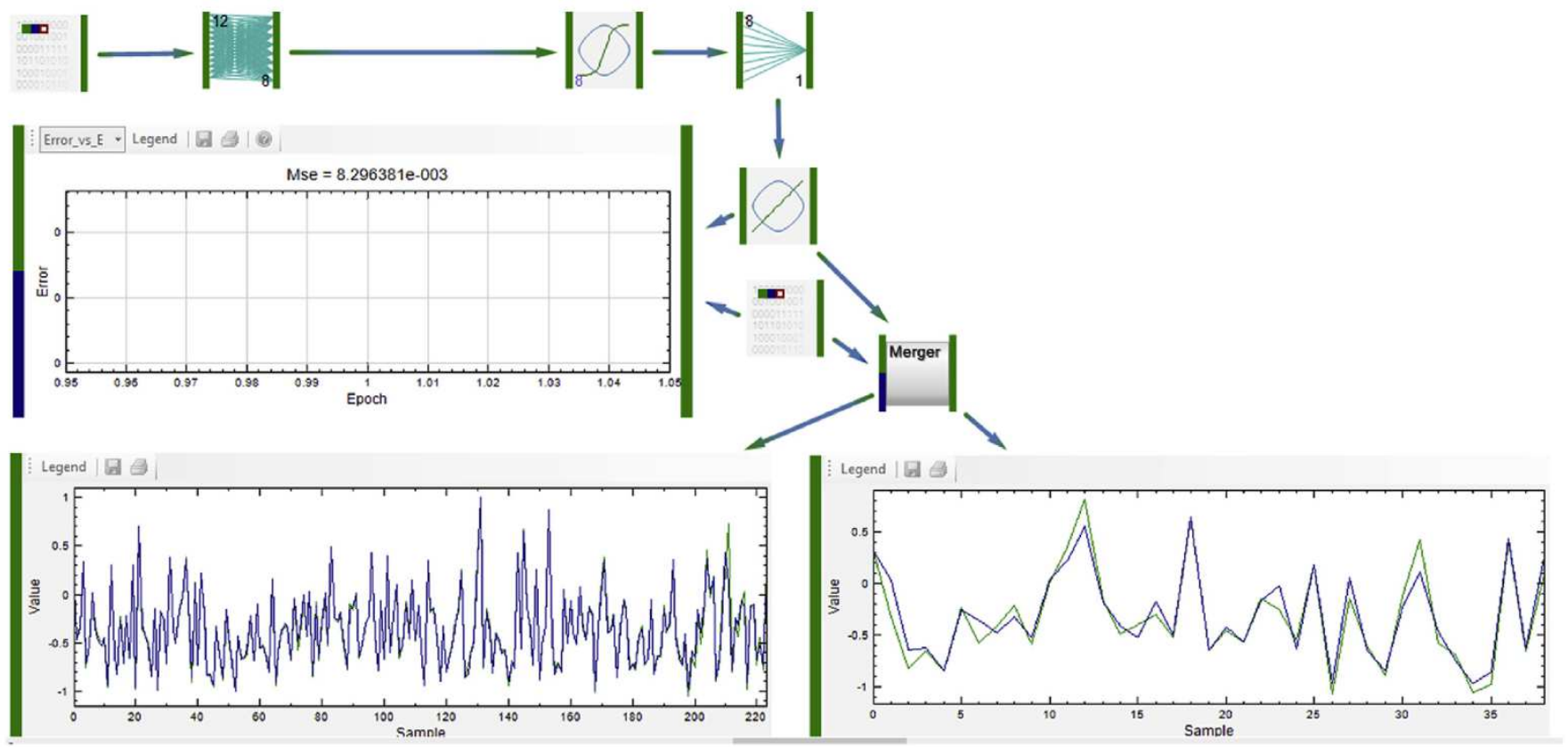

Fig. 4. "A1-ANN" topology.

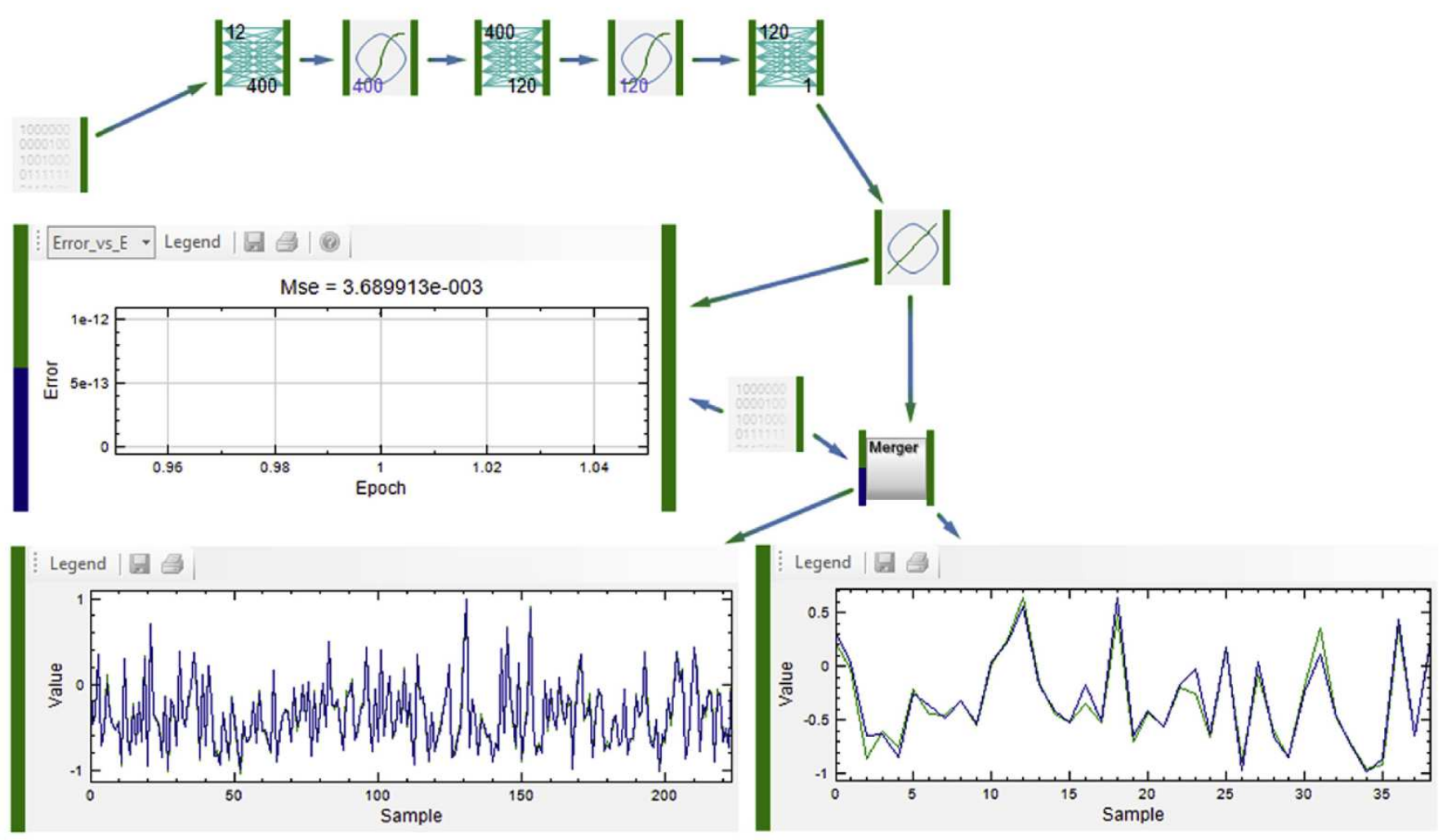

Fig. 5. "B1-ANN" topology.

is defined by the following formula:

$\Phi\left(A_{i}\right)=\frac{1-e^{-K A}}{1+e^{-K A}}$

where $K$ is a constant that controls the shape of the curve. In the A-ANN configuration there is one tanh-sigmoid activation function after the hidden layer, and one linear activation function after the output layer (Fig. 4); in the B-ANN configuration there are two tanh-sigmoid activation functions each after the two hidden layers and one linear activation function after the output layer (Fig. 5). All topologies are characterized by a Back-propagation learning algorithm (Appendix B.1).

To better analyse the reliability of the selected ANNs, different 
Table 3

ANN Design and characteristics.

\begin{tabular}{lllllll}
\hline ANN Design & & & & \\
\hline Models & Topology & Hidden layers & Input layer & $1^{\circ}$ hidden layer & $2^{\circ}$ hidden layer & Learning \\
\hline A1 & Feed forward MLP & 1 & 12 & 8 & - \\
A2 & Feed forward MLP & 1 & 12 & 30 & - \\
B1 & Feed forward MLP & 2 & 12 & 400 & 120 \\
B2 & Feed forward MLP & 2 & 12 & 500 & 250 \\
\hline
\end{tabular}

simulations were carried out changing the time of the training phase and/or the epochs; in all cases, the training phase has been suspended in order to avoid over-fitting. Each ANN was trained and validated; the validation data are extracted from the database before the training phase and represent $15 \%$ of the total data.

The main characteristics of the four ANNs are shown in Table 3:

Given the complexity of the building system that the authors intend to analyse, it would be interesting to investigate the interaction between the different intelligent algorithms in order to exploit the advantages of each technique and get an optimized result.

A hybrid system capable of matching the characteristics of intelligent algorithms can be constituted by ANN and a Genetic Algorithm (GA). The aim is to obtain a computing system that possesses a greater adaptive power with respect to that supplied individually by each of the two approaches; this combination implies a genetic model for the ANN. Indeed, the GA algorithm is used to optimize the ANN architectures. The optimization GA algorithm is based on a population of artificial chromosomes in which the basic characteristics of each ANN configuration containing the starting population are encoded (Appendix B.2). Each network is different from the others with an absolutely random variation of some parameters. Among these parameters are: the initialization of the weight layer, the learning rate, the momentum of the weight layers and of the activation functions, and the numbers of neurons of the hidden layers. The networks that provide an output that most closely matches the optimal output have the greatest reproduction probability and this permits the selecting of the best configuration [49].

The authors, in the initial optimization phase based on the use of the evolutionary process of the GA, identified a population of 20 networks, each of which has random weight values. The evolutionary process is done iteratively for 500 steps or generations to obtain the best configuration network that delivers the optimal combination of key parameters. It was possible to identify the best solution of the problem in a shorter computing time. Thus, the optimization phase processed 10,000 different ANNs each of them trained for only 1000 epochs: a total of $10,000,000$ epochs for the entire process. The simulations were carried out with Peltarion synapse software [50] installed on a machine with Intel Core i5 34604 core with $3.2 \mathrm{GHz}$ processor and $12 \mathrm{~GB}$ of RAM. These features have led to a long time for the optimization phase of the neural network: about 8 days for the most complex (B2-ANN) and about $28 \mathrm{~min}$ for the simplest network configuration (A1-ANN).

\section{Results and discussions}

In the following tables the features of the two best ANN architectures after the optimization phase are shown. In Table 4 the values of learning rate $\eta$, the momentum $\alpha$ and the noise level for each weight layers and activation function for A-ANN topologies are reported. Similarly, in Table 5 the values of $\eta, \alpha$ and noise level are collected for each weight and activation layers for B-ANN topologies.

After the optimization phase, the best four ANN topologies were trained and validated for a total of 100,000 epochs and, based on the machine previously described, the training times are shown in Table 6; the A1 topology is the fastest ( $1 \mathrm{~min}$ and $7 \mathrm{~s}$ ), and the B2 topology the slowest (about $8 \mathrm{~h}$ ).

The post processing phase allows the statistical evaluation of the accuracy of the tested ANNs and the error results are summarized in Table 7 in terms of:

- Mean: the mean value of difference between the expected value and the value predicted by the ANN;

- Median: the intermediate value between all calculated deviations between the expected value and the value predicted by the ANN;

Table 4

Features of the best A-ANN configurations.

\begin{tabular}{|c|c|c|c|c|c|c|c|c|c|c|}
\hline \multirow[t]{2}{*}{ Model A } & \multicolumn{3}{|c|}{$1^{\circ}$ weight layers } & \multicolumn{3}{|c|}{$2^{\circ}$ weight layers } & \multicolumn{2}{|c|}{$\begin{array}{l}1^{\circ} \text { activation } \\
\text { functions }\end{array}$} & \multicolumn{2}{|c|}{$\begin{array}{l}2^{\circ} \text { activation } \\
\text { functions }\end{array}$} \\
\hline & $\eta$ & $\alpha$ & Noise level & $\eta$ & $\alpha$ & Noise level & $\eta$ & $\alpha$ & $\eta$ & $\alpha$ \\
\hline A1 & 0.295 & 0.077 & 0.569 & 0.271 & 0.042 & 0.787 & 0.196 & 0.014 & 0.155 & 0.051 \\
\hline A2 & 0.173 & 0.05 & 0.668 & 0.077 & 0.095 & 0.553 & 0.261 & 0.097 & 0.072 & 0.046 \\
\hline
\end{tabular}

Table 5

Features of the best B-ANN configurations.

\begin{tabular}{|c|c|c|c|c|c|c|c|c|c|c|c|c|c|c|c|}
\hline \multirow[t]{2}{*}{ Model B } & \multicolumn{3}{|c|}{$1^{\circ}$ weight layers } & \multicolumn{3}{|c|}{$2^{\circ}$ weight layers } & \multicolumn{3}{|c|}{$3^{\circ}$ weight layers } & \multicolumn{2}{|c|}{$\begin{array}{l}1^{\circ} \text { activation } \\
\text { functions }\end{array}$} & \multicolumn{2}{|c|}{$\begin{array}{l}2^{\circ} \text { activation } \\
\text { functions }\end{array}$} & \multicolumn{2}{|c|}{$\begin{array}{l}3^{\circ} \\
\text { activation } \\
\text { functions }\end{array}$} \\
\hline & $\eta$ & $\alpha$ & Noise level & $\eta$ & $\alpha$ & Noise level & $\eta$ & $\alpha$ & Noise level & $\eta$ & $\alpha$ & $\eta$ & $\alpha$ & $\eta$ & $\alpha$ \\
\hline B1 & 0.1 & 0.7 & 0.289 & 0.1 & 0.7 & 0.05 & 0.1 & 0.7 & 0.091 & 0.1 & 0.7 & 0.1 & 0.7 & 0.1 & 0.7 \\
\hline B2 & 0.001 & 0.037 & 0.052 & 0.222 & 0.08 & 0.186 & 0.003 & 0.084 & 0.292 & 0.001 & 0.004 & 0.012 & 0.001 & 0.1 & 0.7 \\
\hline
\end{tabular}


Table 6

Data of training phase.

\begin{tabular}{lll}
\hline ANN Training & & \\
\hline Models & Epoch & Training time [s] \\
\hline A1 & 100,000 & 67 \\
A2 & 100,000 & 188 \\
B1 & 100,000 & 12,000 \\
B2 & 100,000 & 28,500 \\
\hline
\end{tabular}

- Standard Deviation (StDv): an estimation of the dispersion of data related to the difference between the expected value and the value issued by the ANN. data.

Each statistical index is calculated for training and validation

The $95 \%$ confidence range values are summed in the last column of Table 7; the bold values indicate the lower absolute values, and generally, the B-ANN architecture has the best results, despite being characterized by longer computational times. Between the two B topologies there are no strong differences; the results are similar. However, the lower computational time of B1 makes it preferable. Meanwhile, between the two A topologies, the best is A1 which is also characterized by a shorter computational time. Comparing the confidence range values of $\mathrm{A} 1$ and $\mathrm{B} 1$ and simultaneously considering the computational time, the A1 topology is preferable. To better understand the validity of these results, in the following figures the error frequency distribution for the training (Fig. 6) and validation phases (Fig. 7) of A1 topology are shown.

After the post processing phase, it is possible to assess the quality of the prediction issued by the ANNs. The statistical analysis performed on the deviation between expected values of heating demand and values predicted by the ANNs confirm the reliability of the neuro-computing approach because the Mean Absolute Error (MAE), calculated for validation phase, is equal to 3.527 for A1 ANN and 3.308 for B1 ANN. Networks that required a longer time to be trained generally show better performance with regard to the accuracy of the calculated values. Nevertheless, the topology A1 network shows an excellent performance in the results belonging to the validation dataset, as can be seen from the $95 \%$ confidence plot in Fig. 8.

In Fig. 8, the $H_{d}$ values of simulated data with the ANN data of the validation data set (the $15 \%$ of $273 H_{d}$ data) are compared. Furthermore, in Fig. 9, the authors display the learning curve of this topology where it is illustrated the trend of the error function of the epochs; an optimal convergence is achieved from about 100 epochs.

To better understand the validity of these results, in the following graphs (Figs.10 and 11) the Absolute Percentage Error (APE), and the Mean Absolute Percentage Error (MAPE), between the simulated data with respect to the ANN data are plotted. Regarding the A1 ANN results Fig. 10 illustrates a MAPE of about $9 \%$ instead the B1 ANN presents a MAPE of about 8.5\% (Fig. 11).

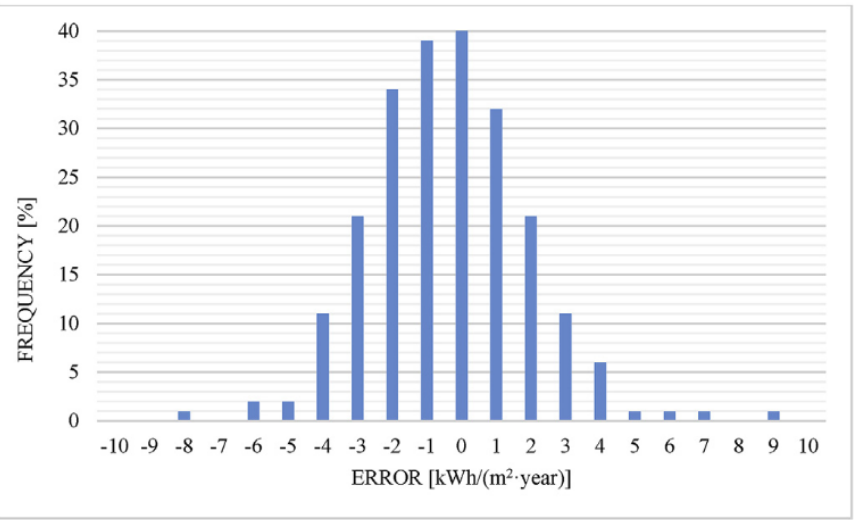

Fig. 6. Error frequency in the training phase of $A 1$ topology.

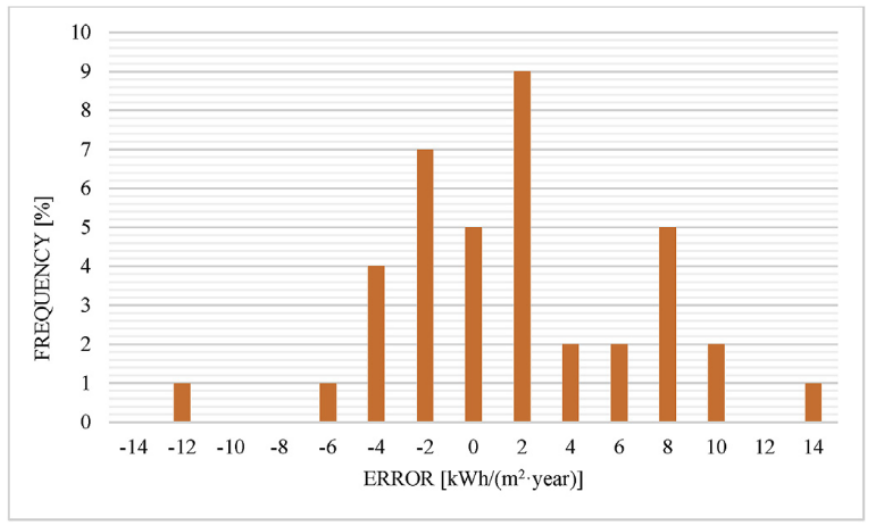

Fig. 7. Error frequency in the validation phase of A1 topology.

The high reliability of the ANNs, configured for the solution of the building thermal balance, are shown in the following figures: the distribution of the desired $H_{d}$ versus the provided A1-ANN is shown, in Fig. 12; the desired $H_{d}$ versus B1-ANN is shown in Fig. 13. In both cases, the data are well distributed on the diagonal of the first quadrant with determination coefficient values $\left(R^{2}\right)$ higher than $95 \%$

\section{Conclusions}

The thermal balance of a building is often influenced by a multitude of physical, environmental and human factors that sometimes influence each other. Consequently, the analysis of a building's energy performance requires substantial input data describing detailed constructions, environmental conditions, thermo-physical properties, building geometry, and control strategies. The evaluation of the thermal load for the winter

Table 7

Post processing error data of ANNs.

\begin{tabular}{|c|c|c|c|c|c|c|c|}
\hline \multicolumn{8}{|c|}{ Post processing error } \\
\hline \multirow[t]{2}{*}{ Models } & \multicolumn{3}{|l|}{ Training } & \multicolumn{3}{|l|}{ Validation } & \multirow{2}{*}{$\frac{\text { Confidence range }}{\left[\mathrm{kWh} /\left(\mathrm{m}^{2} \cdot \text { year }\right)\right]}$} \\
\hline & Mean & Median & StD & Mean & Median & StD & \\
\hline A1 & $-0.869,289$ & $-0.960,003$ & $2.292,850$ & $0.767,037$ & $0.812,436$ & $5.082,879$ & $\pm 9.947,962$ \\
\hline $\mathrm{A} 2$ & $0.048,863$ & $0.230,784$ & $3.641,756$ & $0.839,429$ & $0.951,314$ & $6.318,410$ & $\pm 12.33,428$ \\
\hline B1 & 0.000326 & $0.039,369$ & $1.979,777$ & $1.028,433$ & $0.531,214$ & $4.837,094$ & $\pm 9.572,819$ \\
\hline B2 & 0.000239 & 0.000914 & $2.628,834$ & $0.270,659$ & $1.056,509$ & $4.866,031$ & $\pm \mathbf{9 . 4 2 9 , 1 5 2}$ \\
\hline
\end{tabular}




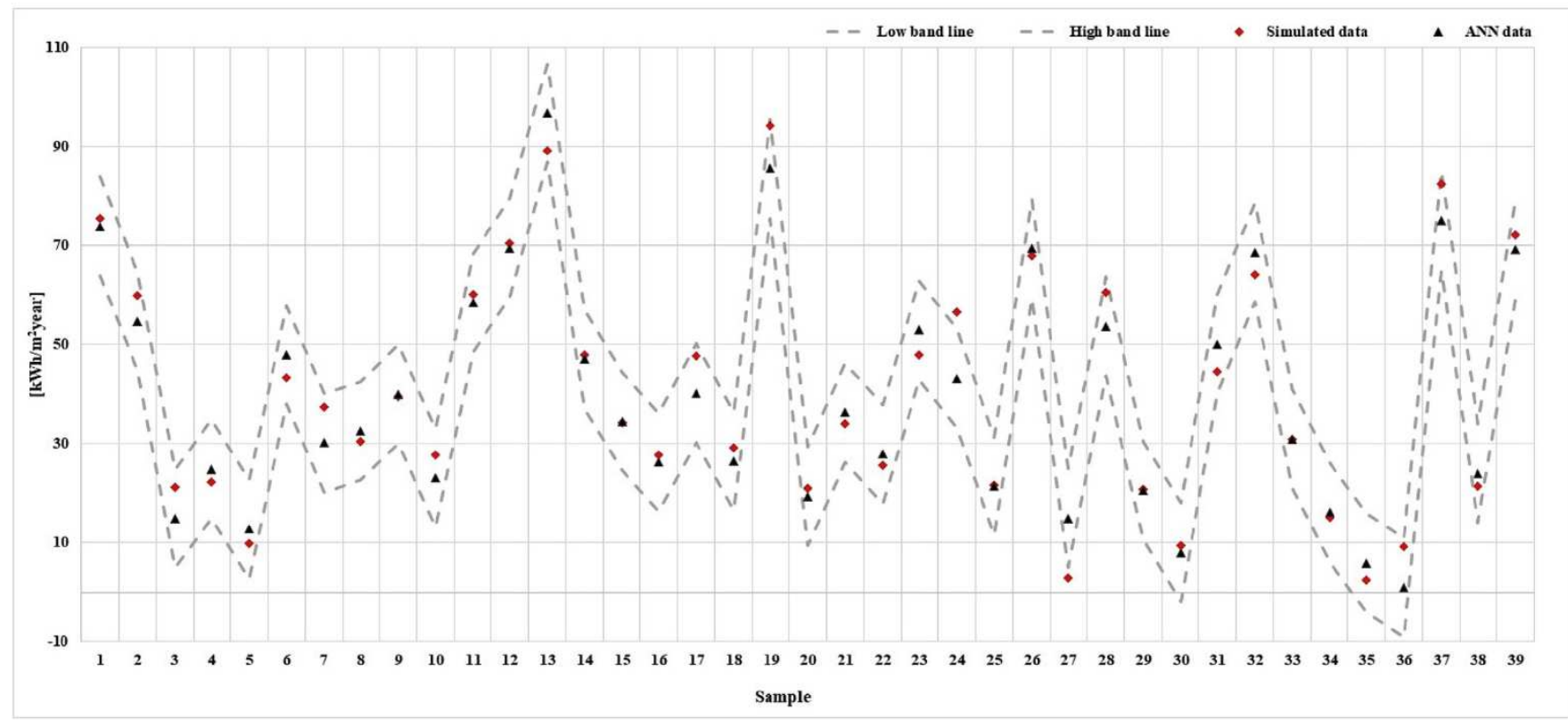

Fig. 8. Confidence plot of MLP A1 topology.
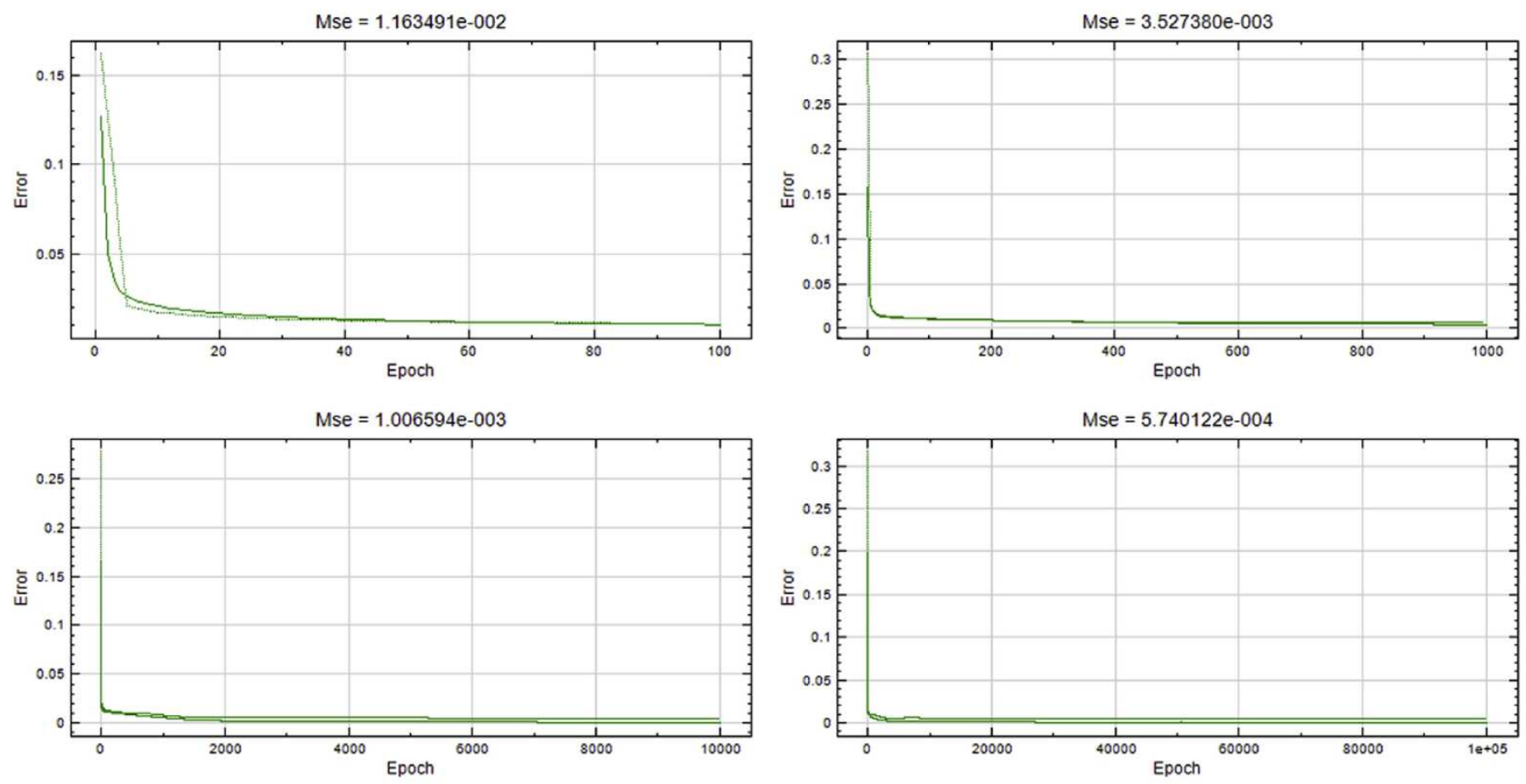

Fig. 9. Learning curves of MLP A1 topology at 100,1,000,10,000 and 100,000 epochs.

conditioning of a building normally requires the adoption of complex and expensive dynamic simulation tools, almost always inaccessible to untrained and non-expert users. Moreover, these tools require a large amount of data, often not available with adequate precision. To make the preliminary assessment of the energy performance of several buildings belonging to a cluster easier and faster, it is more convenient to adopt an alternative approach to detailed dynamic simulations. In this context, it can be extremely advantageous to use neuro-computing, which, based on a large amount of experimental data, can establish dependency relationships between input and output variables.

In this paper, the authors have exploited the power of ANNs to solve the thermal balance of non-residential building designed with high-performance in accordance with European energy standards. With this aim, it was necessary to create a reliable database of training and validation data. The authors have developed a set of models of non-residential buildings with different shapes and characteristics, but all complying with the strictest technical legislation in use in seven countries of the European Union. Furthermore, three different locations have been chosen 


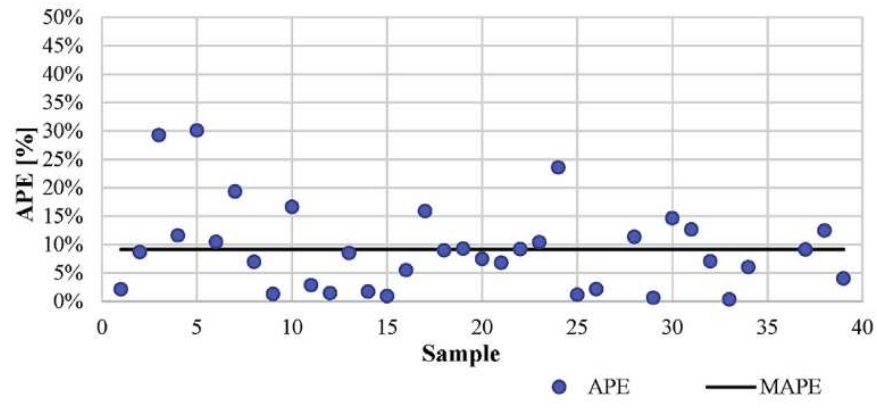

Fig. 10. APE and MAPE of MLP A1validation samples.

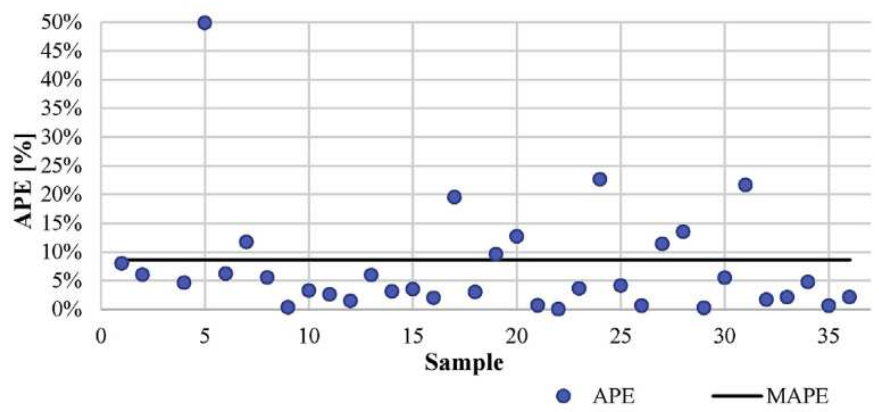

Fig. 11. APE and MAPE of MLP B1validation samples.

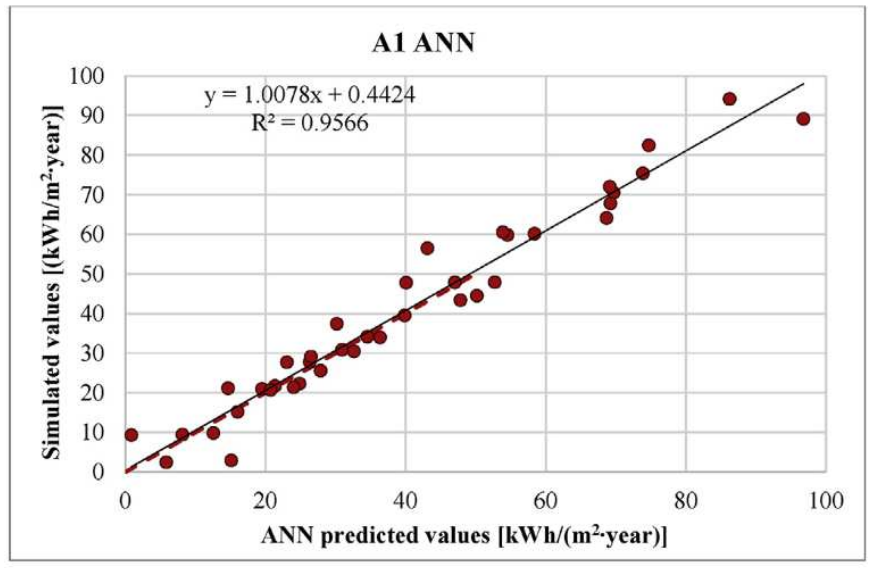

Fig. 12. The distribution of the desired $H_{d}$ versus the provided A1-ANN.

representing different climatic situations in the European territory. As it is well known, the accuracy of the building energy database is essential to obtain a truthful response by an ANN. Indeed, if the data are affected by errors, the ANN learns a wrong relationship. An accurate energy database is guarantee if, as in this case, the simulation data obtained from the dynamic software were correctly calibrated.

Based on this database, four ANNs, with different numbers of neurons and hidden layers were investigated: A1 (8 neurons) and A2 (30 neurons), B1 (400-120 neurons) and B2 (500-250 neurons).

Analysing the data collected in Table 7, it is possible to observe that the B architecture, in general, is characterized by the best results with the lowest MAPE; on the other hand, this configuration required a longer computational time than the $\mathrm{A}$ architecture. Further, the A1 topology is a good compromise between results and computational time. The achievement of these positive results $\left(\mathrm{R}^{2}>95 \%\right)$ confirmed that the ANN application to the heat transfer

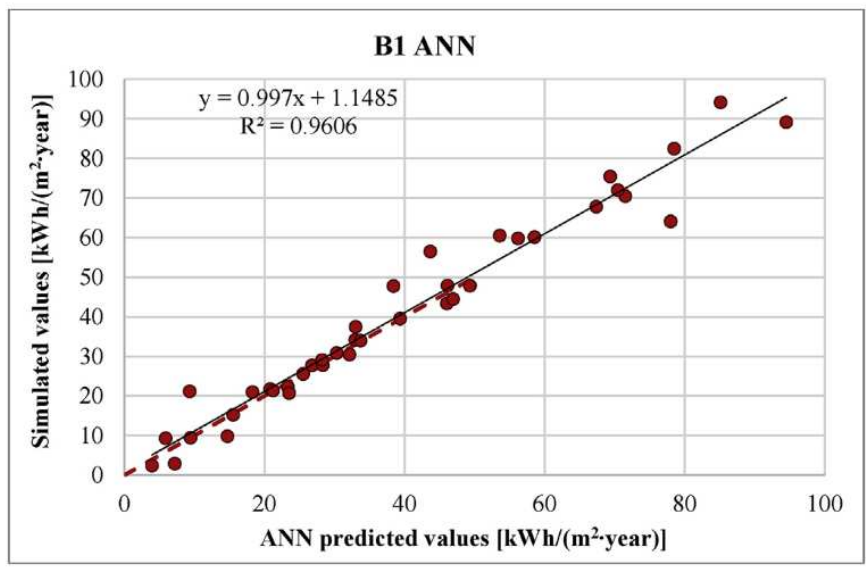

Fig. 13. The distribution of the desired $H_{d}$ versus the provided B1-ANN.

problems in buildings is a valid and attractive alternative solution for thermal balance resolution. Once trained and validated, the ANNs can be easily used, even by users with no specific knowledge in the field of thermo-physical simulation of buildings, to estimate the thermal load necessary for winter air conditioning. Indeed, this method allows the implementation of this algorithm in a software program to act as a suitable decision support tool, which is simple, reliable and handy for immediate use. These first results encourage the authors to explore in the future new and more complex ANN topologies such as the dynamic neural networks.

\section{Appendix A. Supplementary data}

Supplementary data to this article can be found online at https://doi.org/10.1016/j.energy.2019.03.168.

\section{References}

[1] Pacheco R, Ordóñez J, Martínez G. Energy efficient design of building: a review. Renew Sustain Energy Rev 2012;16:3559-73. https://doi.org/10.1016/ J.RSER.2012.03.045.

[2] De Rosa M, Bianco V, Scarpa F, Tagliafico LA. Heating and cooling building energy demand evaluation; a simplified model and a modified degree days approach. Appl Energy 2014;128:217-29. https://doi.org/10.1016/ J.APENERGY.2014.04.067.

[3] D'Amico A, Ciulla G, Panno D, Ferrari S. Building energy demand assessment through heating degree days: The importance of a climatic dataset. Appl Energy 2019;2019(242):1285-306. https://doi.org/10.1016/ J.APENERJY.2019.03.167.

[4] Ciulla G, Lo Brano V, Orioli A. A criterion for the assessment of the reliability of ASHRAE conduction transfer function coefficients. Energy Build 2010;42: 1426-36. https://doi.org/10.1016/j.enbuild.2010.03.012.

[5] Wan KKW, Li DHW, Lam JC. Assessment of climate change impact on building energy use and mitigation measures in subtropical climates. Energy 2011;36: 1404-14. https://doi.org/10.1016/J.ENERGY.2011.01.033.

[6] Directive EE. Directive 2012/27/EU of the european parliament and of the council of 25 october 2012 on energy efficiency, amending directives 2009/ 125/EC and 2010/30/EU and repealing directives 2004/8/EC and 2006/32. Off J L 2012;315:1-56.

[7] Nguyen A-T, Reiter S, Rigo P. A review on simulation-based optimization methods applied to building performance analysis. Appl Energy 2014;113: 1043-58. https://doi.org/10.1016/J.APENERGY.2013.08.061.

[8] Yang L, Yan H, Lam JC. Thermal comfort and building energy consumption implications - a review. Appl Energy 2014;115:164-73. https://doi.org/ 10.1016/J.APENERGY.2013.10.062.

[9] Galatioto A, Ciulla G, Ricciu R. An overview of energy retrofit actions feasibility on Italian historical buildings. Energy 2017;137:991-1000. https://doi.org/ 10.1016/J.ENERGY.2016.12.103.

[10] Omer AM. Energy, environment and sustainable development. Renew Sustain Energy Rev 2008:12:2265-300. https://doi.org/10.1016/J.RSER.2007.05.001.

[11] Omer AM. Renewable building energy systems and passive human comfort solutions. Renew Sustain Energy Rev 2008;12:1562-87. https://doi.org/ 10.1016/J.RSER.2006.07.010.

[12] Bektas Ekici B, Aksoy UT. Prediction of building energy needs in early stage of 
design by using ANFIS. Expert Syst Appl 2011;38:5352-8. https://doi.org/ 10.1016/J.ESWA.2010.10.021.

[13] Moreci E, Ciulla G, Lo Brano V. Annual heating energy requirements of office buildings in a European climate. Sustain Cities Soc 2016;20. https://doi.org/ 10.1016/j.scs.2015.10.005

[14] Li X, Wen J. Review of building energy modeling for control and operation. Renew Sustain Energy Rev 2014;37:517-37. https://doi.org/10.1016/ J.RSER.2014.05.056.

[15] Li X, Wen J, Bai E-W. Developing a whole building cooling energy forecasting model for on-line operation optimization using proactive system identification. Appl Energy 2016;164:69-88. https://doi.org/10.1016/ tion. Appl Energy

[16] Lee Y-S, Tong L-I. Forecasting nonlinear time series of energy consumption using a hybrid dynamic model. Appl Energy 2012;94:251-6. https://doi.org/ 10.1016/J.APENERGY.2012.01.063.

[17] $\mathrm{Hu} \mathrm{M}$. A data-driven feed-forward decision framework for building clusters operation under uncertainty. Appl Energy 2015;141:229-37. https://doi.org/ 10.1016/J.APENERGY.2014.12.047.

[18] Li X, Wen J. Building energy consumption on-line forecasting using physics based system identification. Energy Build 2014;82:1-12. https://doi.org/ 10.1016/J.ENBUILD.2014.07.021.

[19] Satyavada H, Baldi S. An integrated control-oriented modelling for HVAC performance benchmarking. J Build Eng 2016;6:262-73. https://doi.org/ 10.1016/j.jobe.2016.04.005.

[20] Afram A, Janabi-Sharifi F, Fung AS, Raahemifar K. Artificial neural network (ANN) based model predictive control (MPC) and optimization of HVAC systems: a state of the art review and case study of a residential HVAC system. Energy Build 2017;141:96-113. https://doi.org/10.1016/ j.enbuild.2017.02.012

[21] Crawley DB, Hand JW, Kummert M, Griffith BT. Contrasting the capabilities of building energy performance simulation programs. Build Environ 2008;43: 661-73. https://doi.org/10.1016/J.BUILDENV.2006.10.027.

[22] Kramer R, van Schijndel J, Schellen H. Simplified thermal and hygric building models: a literature review. Front Archit Res 2012;1:318-25. https://doi.org/ 10.1016/J.FOAR.2012.09.001.

[23] ISO, EN. EN ISO 13790: 2008. Energy performance of buildings-Calculation of energy use for space heating and cooling. Brussels: Eur Comm Stand (CEN); 2008.

[24] ASHRAE. Energy conservation in new building design - ASHRAE Standard 90A-1980 1980.

[25] Cellura M, Lo Brano V, Mistretta M, Orioli A. To assess the validity of the transfer function method: a neural model for the optimal choice of conduction transfer functions. ASHRAE Transact 2010;116(2):585-96.

[26] Beccali M, Ciulla G, Brano V Lo, Galatioto A, Bonomolo M. Artificial neural network decision support tool for assessment of the energy performance and the refurbishment actions for the non-residential building stock in Southern Italy. Energy 2017. https://doi.org/10.1016/j.energy.2017.05.200.

[27] Klein SA. Others. TRNSYS-A transient system simulation tool, ver 14.2 . MadLson, WI: Sol Energy Lab Univ Wisconsin; 1996.

[28] Ciulla G, Lo Brano V, D'Amico A. Modelling relationship among energy demand, climate and office building features: a cluster analysis at European level. Appl Energy 2016. https://doi.org/10.1016/j.apenergy.2016.09.046.

[29] Wijayasekara D, Manic M, Sabharwall P, Utgikar V. Optimal artificial neural network architecture selection for performance prediction of compact heat exchanger with the EBaLM-OTR technique. Nucl Eng Des 2011;241:2549-57. https://doi.org/10.1016/J.NUCENGDES.2011.04.045.

[30] Demuth HB, Beale MH, De Jess O, Hagan MT. Neural network design. Martin Hagan; 2014.

[31] Danaher S, Datta S, Waddle I, Hackney P. Erosion modelling using Bayesian regulated artificial neural networks. Wear 2004;256:879-88. https://doi.org/ 10.1016/J.WEAR.2003.08.006.

[32] Haykin S. Neural networks: a comprehensive foundation. first ed. Upper Saddle River, NJ, USA: Prentice Hall PTR; 1994.

[33] Neuron Diagram \& types | ASU - Ask a biologist n.d. https://askabiologist.asu. edu/neuron-anatomy (accessed December 22, 2017).

[34] Angelini E, di Tollo G, Roli A. A neural network approach for credit risk evaluation. Q Rev Econ Finance 2008;48:733-55. https://doi.org/10.1016/ J.QREF.2007.04.001.

[35] Lo Brano V, Ciulla G, Di Falco M. Artificial neural networks to predict the power output of a PV panel. Int J Photoenergy 2014;2014. https://doi.org/ $10.1155 / 2014 / 193083$

[36] Pacelli V, Azzollini M. An artificial neural network approach for credit risk management. J Intell Learn Syst Appl 2011;3:103.

[37] Ciulla G, D'Amico A, Di Dio V, Lo Brano V. Modelling and analysis of real-world wind turbine power curves: Assessing deviations from nominal curve by neural networks. Renew Energy 2019;2019(140):477-92. https://doi.org/ 10.1016/J.RENENE.2019.03.075.

[38] Lo Brano V, Ciulla G, Beccali M. Application of adaptive models for the determination of the thermal behaviour of a photovoltaic panel. Lect Notes Comput Sci (including Subser Lect Notes Artif Intell Lect Notes Bioinformatics) 2013;7972:344-58. https://doi.org/10.1007/978-3-642-39643-4_26. LNCS.

[39] Asadi E, da Silva MG, Antunes CH, Dias L. Multi-objective optimization for building retrofit strategies: a model and an application. Energy Build 2012;44: 81-7. https://doi.org/10.1016/J.ENBUILD.2011.10.016.

[40] Principe JC, Euliano NR, Lefebvre WC. Neural and adaptive systems: fundamentals through simulations, vol. 672. New York: Wiley; 2000.

[41] Society of heating refrigerating A, air conditioning engineers. ASHRAE STANDARD: an American Standard: thermal Environmental Conditions for Human Occupancy. American Society of Heating refrigerationg and air conditioning engineers; 1992.

[42] Feng Y. Thermal design standards for energy efficiency of residential buildings in hot summer/cold winter zones. Energy Build 2004;36:1309-12. https:// doi.org/10.1016/J.ENBUILD.2003.08.003.

[43] Davies MG. Building heat transfer. John Wiley \& Sons; 2004.

[44] Tank AK, Wijngaard J, Van Engelen A. Climate of Europe. Assess. Obs. Dly. Temp. Precip. Extrem.. the Netherlands: KNMI De Bilt; 2002.

[45] version 4.0 Meteonorm. METEONORM: global meteorological database for solar energy and applied climatology. Solar Engineering Handbook. Meteotest: Bern; 1999.

[46] EIA US. Monthly energy review. Energy Inf Adm US. 2014.

[47] Ciulla G, Lo Brano V, D'Amico A. Numerical assessment of heating energy demand for office buildings in Italy. Energy Procedia 2016;101. https:// doi.org/10.1016/j.egypro.2016.11.029.

[48] Ciulla G, D'Amico A, Lo Brano V. Evaluation of building heating loads with dimensional analysis: application of the Buckingham $\pi$ theorem. Energy Build 2017;154:479-90. https://doi.org/10.1016/J.ENBUILD.2017.08.043.

[49] Floreano D, Mattiussi C. Manuale sulle reti neurali. 2002.

[50] Peltarion [n.d.] 